\title{
Prevalence and Recovery from Newly Onset Anosmia and Ageusia in Covid 19 Patients at our Teritary Care Centre
}

\author{
Vinod T. Kandakure ${ }^{1} \cdot$ Harshala R. Valvi ${ }^{1}$ Pradipkumar Khokle $^{1} \cdot$ \\ Madhuri S. More ${ }^{1} \cdot$ Ritika Chouhan $^{1}$
}

Received: 10 February 2021 / Accepted: 31 March 2021/Published online: 10 April 2021

(C) Association of Otolaryngologists of India 2021

\begin{abstract}
Anosmia (loss of smell) and Ageusia (loss of taste) are newly presenting independent symptoms in association with multiple symptoms such as Fever, Dry cough and Breathlessness in COVID 19 Patients.The Study of aims is to estimate Prevalence of Anosmia \& Ageusia in Confirmed Covid 19 cases and to assess their Recovery rates. A Study conducted between June 2020 and September 2020 at a tertiary care COVID Dedicated hospital. Total 200 patients with age group 12-70 years Confirmed COVID 19 Positive Patients using RTPCR having mild to moderate symptoms were included. Patients were examined Clinically alongwith all safety measures to analyse prevalence \& estimate their recoveries from sensory impairement using 10 item based DyNaCHRON questionnaire(concerned with taste and smell) at 10th, 14th \& 21st Day. Out of 200 patients, Prevalence of Isolated Ageusia is 7\%, Isolated Anosmia 4.5\% and with Anosmia and Ageusia 4\%. Complete Recovery regained in Ageusia within 14 days, while Rest all patients of Anosmia and both (Anosmia and Ageusia) within 21 days, Except 2 patients where long term Anosmia persists. Newly onset Anosmia and Ageusia are common in early stages of Covid 19 disease. They are Prevalent in mild to moderate symptomatic form of Diseases. Recovery in most cases is rapid and complete.Early Screening tests performed in suspected COVID 19 patients with loss of taste and smell sensation allows early diagnosis and treatment.
\end{abstract}

Vinod T. Kandakure

vinodkandakure@gmail.com

1 Department of ENT, Vilasrao Deshmukh Government Institute of Medical Sciences, Latur, Maharashtra, India
Keywords Covid $19 \cdot$ Anosmia $\cdot$ Ageusia Prevalence Recovery

\section{Introduction}

New Coronavirus Disease 2019 (Covid 19) is a highly contagious Zoonosis named by WHO in February 2020 Caused by SARS-CoV-2 that rapidly transmitted from human to human by respiratory secretions has rapidly evoluted into global pandemic [1-3].

SARS-CoV-2 belongs to the coronaviridae family along with SARS-CoV and MERS-CoV. It has a single stranded RNA genome [4]. Four human coronaviruses produce symptoms that are generally mild respiratory illness such as common cold in humans. (i) Human coronavirus OC43 (HCoV-OC43) beta-CoV. (ii) Human coronavirus HKU1(HCoV-HKU1) beta CoV. (iii) Human coronavirus 229E (HCoV-229E) alpha-CoV. (iv) Human coronavirus NL63 (HCoV-NL 63) alpha CoV [5]. Three human coronavirus produce symptoms that are potentially Severe (a) Middle east respiratory syndrome- related coronavirus (MERS-CoV), beta CoV outbreaks began in $2012[6,7]$. (b) Severe acute respiratory syndrome coronavirus (SARS$\mathrm{CoV}$ ) beta $\mathrm{Cov}$ which leads to SARS epidemic in 2002-2004 [8, 9]. (c) Severe acute respiratory syndrome coronavirus 2 SARS-CoV-2 Beta $\mathrm{CoV}$ Outbreaks 2019-2020 [10].

There was a rapid increase in number of unidentified case of pneumonia in December 2019, detected in Wuhan City, Hubei Province in China [11]. Throat swab samples were taken of such cases Causative Microorganisms was identified at Chinese Centre of Disease Control \& Prevention (CCDC) on 7th January 2020 named as Severe Acute Respiratory Syndrome Coronavirus-2 (SARS-Cov-2 
[12]. During outbreaks of Covid 19 infections, there are millions of infected people with thousand dead all over world remains a global treat [13].This is the third novel coronavirus in last 17 years and phylogenetically it is close related to bat derived SARS like coronavirus [14].

Covid 19 positive patients characterised by variety of clinical manifestation typically high fever appears after dry cough. Some clinical pneumonitis develops and progress resulting in shortness of breath $[15,16]$. According to severe epidemological studies, it could case olfactory and gustatory dysfunction especially mild to moderate form Covid 19 infected cases [17-20].

Anosmia (loss of smell) and Aguesia (loss of taste) are newly presenting independent symptoms [21] with common symptoms such as fever, dry cough \& shortness of breath in COVID $19+$ ve cases. They are also associated with muscle ache (myalgia) headache, sore throat, rhinorrhoea, chest pain, diarrhoea, nausea/vomiting, conjunctival, Nasal congestion, Sputum production, fatigue, hemoptysis and chills [22-26].

Some authors reported three mechanisms for anosmia in covid 19 patients; (i) local infection of support cells and vascular pericytes in the nose and olfactory bulb that may affect the function of bipolar neurons or mitral cells. (ii) Damage to support in the sensory epithelium that may indirectly influence the signaling pathway from sensory neurons to the brain and. (iii) Damage to sustentacular cells and bowman gland cells that could leads to diffuse morphological damage to the olfactory sensory epithelium and altering the smell perception [27, 28].

$\mathrm{Hu}$ el at studied the cellular distribution of taste cells and ACE 2 Receptor distribution. They found that the percentage of ACE positive cells was higher in taste cells, which indicated that SARS-COV-2 might invade them and leads to ageusia in these patients. However, data regarding the exact mechanism by which SARS-COV-2 determines ageusia is limited. The virus may bind to the sialic acid receptors and occupy and accelerate the degradation of the gustatory particles leading to decrease in taste sensation [29].

Infection of upper respiratory tract can cause acute onset anosmia because of viral damage to olfactory epithelium [30]. Damage to olfactory nerve during invasion and multiplication of SARS-CoV-2 may explain anosmia may be more frequently observed in Covid 19 patients other than respiratory viral infections.

Aguesia may be secondary result of olfactory dysfunction, however angiotension converting enzyme 2 receptors which is main host cell receptor of SARS-CoV-2 for binding \& penetrating cells widely expressed on epithelial cells of oral mucosa [31]. Damage of this mucosal epithelial cells may explain ageusia i.e. observed in early stage of COVID 19.The evidence may explain pathogenic mechansim underlying anosmia and ageusia in covid 19 [32].

Since there have been a rapidly growing reports of significant increase in number of patient presenting with loss of smell and taste with or without associated symptoms they also affect quality of life.

For this purpose we decided to assess the prevalence of olfactory and gustatory disorders in infected covid 19 positive patients and to analyze their olfactory and gustatory recovery.

\section{Aims and Purpose}

- To describe the Prevalence and characterize occurrence of subjective olfactory and gustatory dysfunctions in patients with laboratory confirmed COVID 19 infections.

- Estimate Recovery Rates from sensory disorders with laboratory confirmed COVID 19 infections.

\section{Methods and Materials}

A study was conducted between June and September 2020 at tertiary care covid dedicated hospital.

Total 200 patients with age group 12-70 years with laboratory confirmed COVID 19 infections using reverse transcriptase polymerase chain reaction (RT-PCR)Positive having mild to moderate $(\mathrm{SpO} 2>95 \%)$ symptoms were included in study.

Mild symptoms from only low grade fever, mild cough and slight fatigue with moderate symptoms from high grade fever, shortness of breath upto pneumonitis seen in chest radiograph.

Patients with confirmed RT-PCR positive testing for the SARS-CoV-2 viral genome were assessed for symptoms and signs of olfactory and taste disturbance.

A study conducted smell and taste sensations clinically along with phone interview to analyse the prevalence and estimate recovery Using a 10 item based DyNaCHRON (Dysfonctionnement Nasal Chronique $=$ Chronic Nasal dysfunction) questionnarrie (concerned with taste and smell) on 10th, 14th and later 21st day. (Table 1). Patient tested For smell sensation with Spirit, Rose water, while for taste sensation with Jaggery, salt, lemon etc.

Recovery at Day 10, 14 \& 21; Score between 0-5 and 100-Complete Recovery, Score between 5 and 1st score obtained at day 10 out of 100-Partial Recovery, Score equal or Superior to 1 st score obtained at day 10 out of 100-No Recovery.

Ethical committee clearance were taken. 
Table 1 DyNaCHRON Questionnaire translated

Olfactory loss self assessment grid (extracted from the DyNaCHRON questionnaire first 10 questions)

Circle a number between 0 and 10

1 Do you experience difficulty smelling things? 0,123,456,789 10

2 Do you feel it hard to detect "dangerous" smells (gas, petrol, smoke, smell of something burning...)? 0,123,456,789 10

3 Do you experience different perceiving kitchen smells (smell of coffee, hot bread, a dish that is shimmering or being heated up...)? $0,123,456,78910$

4 Do you have difficulty recognizing the taste of food?0,123,456,789 10

5 Do you have difficulty perceiving the smell of hygiene products (soap, cologne, perfume, household cleansing products...)? $0,123,456,789$ 10

6 Do you experience difficulties detecting "bad smells"(toilets, decomposing matter, certain chesses, sweat...)? 0 12 3,456,789 10

7 Does it bother you not to perceive your own body smells (perspiration, WC ...)? 0,123,456,789 10

8 Does it bother you not to smell the body smell of others ?0,123,456,789 10

9 Do you experience difficulty perceiving the sweet or savory taste of food ? 012345678910

10 Does this difficulty smelling affect your mood?0,123,456,789 10

A written informed consent were taken from all patients to be part of the study.

Data were recorded in excel sheet and analyzed.

\section{Inclusion Criteria}

- Patients with laboratory confirmed COVID19 infection using Reverse transcriptase polymerase chain reaction (RT-PCR).

- Age group between 12 and 70 years.

- Both sexes are included.

- Patients clinically stable and having Mild to moderate symptoms able to complete the questionnaire.

\section{Exclusion Criteria}

- Age $<12 \&>70$ yrs years old.

- Not confirmed positive RTPCR test result.

- Patients with Previous history of loss of smell, taste or both before the study.

- Patients with Previous history of head trauma, acute or chronic rhinosinusitis, allergic rhinitis, dementia, malignancy or abnormal nasal anatomy.

- Severe Respiratory failure/symptoms or treatment in the Intensive care unit having $\mathrm{SpO} 2$ below $95 \%$ at time of study.

- Psycological disturbances

- Those who lost to follow up (not responding to 3 telephonic call).

\section{Results}

In our study, 200 COVID 19 patients with RTPCR positive test with mild \& moderate symptoms, the Pevalence rate of Anosmia,Ageusia and combined symptoms were evaluated comprising 109 Males and 91 Females within age group of $12-70$ years.

$54.5 \%$ Males are commonly affected with Chemosensory dysfunction than $45.5 \%$ Females (Fig. 1). Males are frequently affected with Ansomia (67\%) more than Ageusia (57\%) as shown in (Fig. 2).

Maximum age group commonly affected $31-40$ years which is $35.5 \%$,so younger individuals are affected (Fig. 3).

$29 \%$ patients with Chemosensory dysfunction were associated with Comorbidites. Amongst them Anosmia $(33 \%)$ are highly affected with comorbidites than Ageusia $(28.75 \%)$ and combined symptoms (25\%).Hypertension

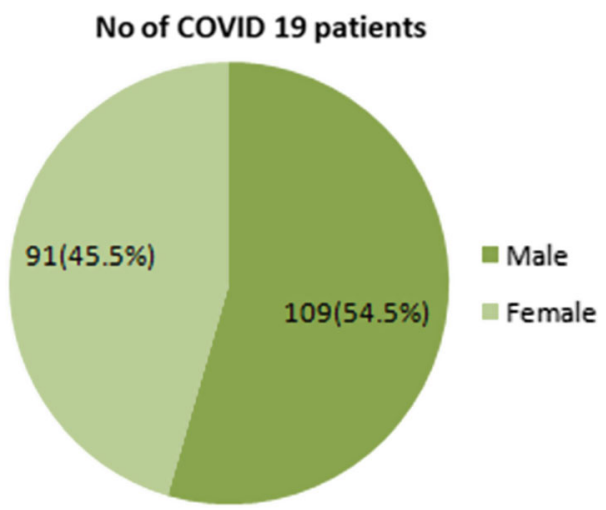

Fig. 1 Showing Gender distribution of patient studied 


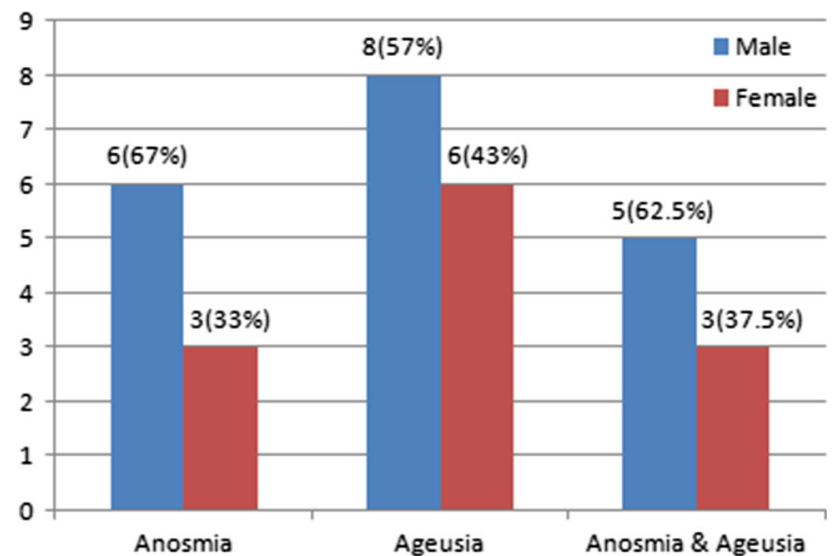

Fig. 2 Gender distribution in COVID 19 positive patients related to Chemosensory Dysfunction

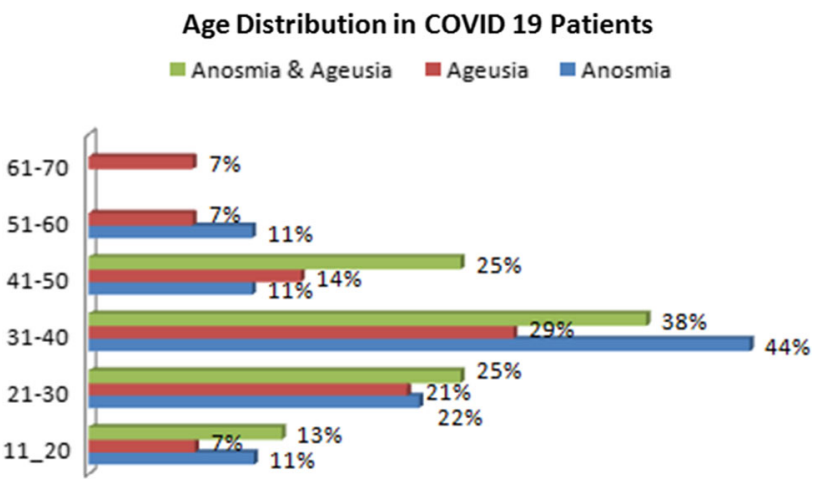

Fig. 3 Age distribution amongst COVID 19 Patient studied

(44\%) and Diabetes (33\%) are higher comorbidites (Table 2).

So Prevalence rate of Ageusia is 7\% Anosmia 4.5\% and Both (Anosmia and Ageusia) 4\%. (Fig. 4), while comparison studies are shown in (Table 3).

Recoveries from sensory dysfunction at 10th, 14th and 21st day Complete recovery obtained Ageusia within 14 days ( 2 weeks), while Rest all patients of Anosmia and combined symptoms Complete recovery obtained within
21 days (3 weeks) except 2 patients where long term Anosmia persists (Table 4).

\section{Discussion}

COVID-19 manifests with wide clinical spectrum ranges from no symptoms to septic shock and multi organ dysfunctions.

Chemosensory dysfunctions are known to be common problems during the COVID-19 pandemic. Olfactory and Gustatory Dysfunction (OGD) along with other classical COVID 19 symptoms such as fever, cough and sore throat were experienced by 31 patients $(15.5 \%)$ out of 200 patients. Amongst them, 13 patients $(42 \%)$ experienced OGD before presentation, while 18 patients $(58 \%)$ had only OGD at the time of presentation with other classic COVID 19 symptoms. Therefore these disorders are indicators of early cases of COVID 19 diseases and necessary for screening and infection control.

Our study design includes Questionaairre about loss of smell and taste clinically on 10th, 14th and 21st day. During hospital stay we analyze improvement of symptoms in patients treated with Antibiotics, T. Cetrizine, Multivitamin and Multiminerals, T. zinc, Steam inhalation and Nasal saline drops. As per protocol after Covid 19 negative report at the end of 14 th day patients gets discharged. Later follow up was done on 21st day.

Complete recovery obtained in Majority of patients with Ageusia, Anosmia and both within 14-21 days due to medications while 2 patients have Persistance Sensory dysfunction after 21 st day are referred to specialist of smell and taste clinics for rehabiliatation.

According to Study conducted by Harvard medical school for covid 19 suggest that viral load is a key factor to determine if covid patients is more susceptible to long term anosmia, when SARS-CoV-2 invades cells, it causes inflammation that knocks out sense of smell.so recovery time is related to how long the surrounding cells will take

Table 2 Showing distribution of comorbidities amongst COVID 19 patients with chemosensory dysfunction

\begin{tabular}{lllll}
\hline Comorbidites & Ageusia $(\mathrm{n}=14)$ & Anosmia $(\mathrm{n}=9)$ & Ageusia and Anosmia $(\mathrm{n}=8)$ & Total $(\mathrm{n}=31)$ \\
\hline Hypertension & $2(50 \%)$ & $1(33.33 \%)$ & $1(50 \%)$ & $3(44.44 \%)$ \\
Diabetes & $1(25 \%)$ & $1(33.33 \%)$ & $1(50 \%)$ & $1(11.11 \%)$ \\
Asthma/COPD & & $1(33.33 \%)$ & & $1(11.11 \%)$ \\
Thyroid Diseases & $1(25 \%)$ & & & $9(29 \%)$ \\
Heart diseases & & & $2(25 \%)$ & \\
Renal diseases & $4(28.75 \%)$ & $3(33.33 \%)$ & & \\
Total & &
\end{tabular}


Fig. 4 Prevalence Rate of Isolated Anosmia, Isolated Ageusia and Anosmia \& Ageusia in Confirmed COVID 19 positive Patients
Prevalence Rate \%

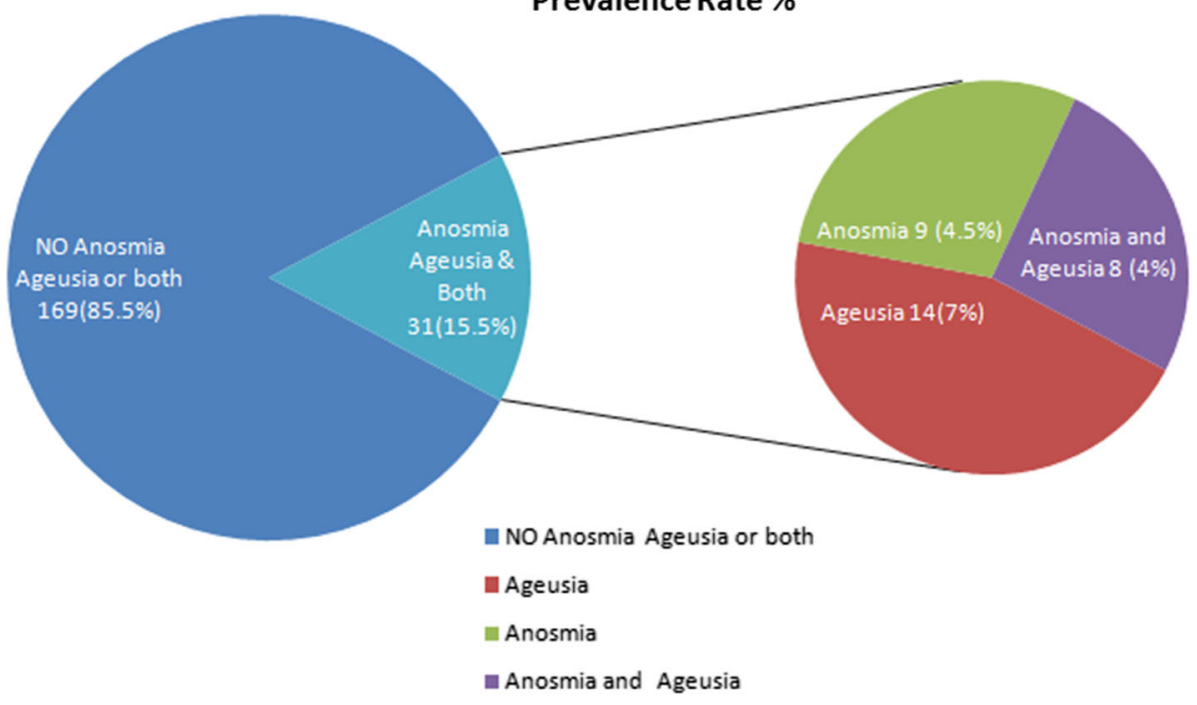

Table 3 Comparsion of our study with other studies for prevalence rate

\begin{tabular}{|c|c|c|c|c|c|}
\hline Study & Year of study & Anosmia & Ageusia & Anosmia and Ageusia & Total \\
\hline Present study & June-September 2020 & $4.5 \%$ & $7 \%$ & $4 \%$ & $15.5 \%$ \\
\hline Patil et al [40] & September 2020 & $4.75 \%$ & $7.15 \%$ & $4.25 \%$ & $16.15 \%$ \\
\hline AL-Ani et al [41] & May-june 2020 & $4.96 \%$ & $11.35 \%$ & $8.51 \%$ & $24.82 \%$ \\
\hline Mayo et al (42) & May 2020 & $3.2-9.83 \%$ & $5.6-62.7 \%$ & & \\
\hline
\end{tabular}

Table 4 Showing Recovery from Chemosensory dysfunction amongst COVID 19 Positive patients studied

\begin{tabular}{|c|c|c|c|c|}
\hline Symptoms & $\begin{array}{l}\text { Complete recovery at } 10 \text { th day no. } \\
(\%)\end{array}$ & $\begin{array}{l}\text { Complete recovery at } 14 \text { th day no. } \\
(\%)\end{array}$ & $\begin{array}{l}\text { Complete recovery at } 21 \text { st day no. } \\
(\%)\end{array}$ & Total \\
\hline Ageusia & $10(71.42 \%)$ & $4(28.57 \%)$ & 0 & 14 \\
\hline Anosmia & $6(66.66 \%)$ & $1(11.11 \%)$ & $1(11.11 \%)$ & 9 \\
\hline $\begin{array}{l}\text { Anosmia and } \\
\text { Ageusia }\end{array}$ & $5(62.5 \%)$ & $1(12.5 \%)$ & $1(12.5 \%)$ & 8 \\
\hline
\end{tabular}

time to heal depending on supply of stem cell within nose lining.

In a study conducted by Sakalli et al. (June 2020), out of 172 patients, mean age $37.8 \pm 12$ years with range of 18-65 years, $51.2 \%$ were females. The most prevalent comorbidities in these patients were allergic rhinitis in $8 \%$, high blood pressure in 5\%, depression in $4 \%$ asthma in $3 \%$, diabetes in $3 \%$, renal disease in $2 \%$ thyroid disease in $2 \%$, heart problems in $2 \%$ \& autoimmune disease in $2 \%$. Sakalli [33].

A study published by Lechien et al. (March 2020) total 417 patients, mean age of patients was $36.9 \pm 11.4$ years (range 19-77). There were 263 females and 154 males. The most prevalent comorbidities of patients were allergic rhinitis, asthma, high blood pressure and hypothyroidism [34].

In a study conducted by Shah et al. [35] (April-August 2020) by a Total 655 patients, mean age was $32.7 \pm 10.1$ years with a range of $19-85$ years. In their study, 414 (63.20\%) patients were males and 241 (36.80\%) were females. Hypertension (15.79\%) and hypothyroidism $(10.52 \%)$ were most frequent comorbidities in patients. Males have greater predisposition to olfactory dysfunction because they have higher livelihood of exposure to harmful agents.in adddition estrogen and progesterone might have favourable impacts in peripheral or central olfactory region stem cells that could delay olfactory decline in women $[36,37]$ moreover neural function has propensity to 
diminish more rapidly in mens as compared to womens [38, 39].

In our study, out of 200 patients, mean age is $30 \pm 5$ years with range of 12-70 years. In our study, 109 $(54.5 \%)$ patients were males and $91(45.5 \%)$ patients were females. Hypertension (44\%) and Diabetes (33\%) were most frequent comorbidities in patients.

A study published by lechien et al. (2020) described short term, olfactory rates complete recovery rate of 59 (44\%) patients within 5-8 days following resolution of general symptoms.in total $72.6 \%$ of these patients recovered olfactory functions within first 8 days following resolution of the diseases.

In a study conducted by Sakalli E et al., (2020) Recovery status of loss of smell.Total 69 (78.4\%) patients with $16(18.2 \%)$ patients showing mild recovery,33 (37.5\%) patients showing moderate recovery \& $20(22.7 \%)$ patients showing complete recovery. Recovery status of loss of taste total of $63(77.8 \%)$ patients with $17(21 \%)$ patients showing mild recovery, 27 (33.33\%) patients showing moderate recovery and 19 (23.4\%) patients showing complete recovery.

In our study, patients were followed up at end of 10th, 14 th day \& later on 21 st day for improvement of symptoms. Out of 14 patients Loss of taste sensation,

10 patients $(71.42 \%)$ recovered spontaneously at end of 10th day, remaining 4 patients regained their sensations after 14st day. Out of 9 patients with loss of smell sensation, 5 patients $(55.55 \%)$ recovered spontaneously at end of 10th day, remaining 1 patients $(11.11 \%)$ regained their sensation after 14 th day and 1 patient $(11.11 \%)$ at end of 21 st day. Out of 8 patients with loss of both (smell \& taste sensation), 5 patients $(62.5 \%)$ recovered spontaneously at end of 10th day, while remaining 1 patients $(12.5 \%)$ regained their sensation after 14th day while 1 patient regained sensations completely at end of 21 st day while 2 patients did not regain their sense after 21st days too.

For Early Recovery of taste bud stimulation and smell stimulation with rose water and lemon. Olfactory and gustatory neurons have capability to regenerate with daily twice sniffing of rose water and lemon taste.

The pathophysiology of loss of smell developing after infection with this virus has been suggested to be due to olfactory epithelial damage or due to spread to central nervous system. The behaviour of SARS-CoV-2 is different in different patients. This prevents suspicion of diseases clinically delay diagnosis and isolation of patients infected with virus making it difficult to deal with the diseases.

Though the mechanisms for the smell and taste loss in COVID 19 disease are unclear, we observed that SARSCoV-2 does cause anosmia and ageusia in infected patients and presents as symptoms alone.
The condition may improve gradually on its own with majority recover spontaneously or may remain same. Consideration of Loss of Smell and taste as part of screening and diagnostic approaches for COVID 19 could improve case detection and further spread of infection in community with early isolation and treatment.

\section{Conclusion}

Newly onset anosmia and ageusia are common in early stages of Covid 19 disease affecting more commonly in younger Males.

Anosmia and Ageusia are prevalent in mild to moderate symptomatic form of Diseases.

Anosmia are highly affected with comorbidites than ageusia with higher comorbidities as hypertension and Diabetes.

Recovery in most cases are rapid and complete.

First recovery of smell and taste sensation is improved in patients with Regular Rose water inhalation and use of lemon So it is advised.

Early Screening tests performed in suspected COVID 19 patients with loss of taste and smell sensation allows early diagnosis and treatment.

\section{Declarations}

Conflict of interest The authors declare that they have no competing interest.

\section{References}

1. Xu X-W, Wu X-X, Jiang X-G et al (2020) Clinical findings in a group of patients infected with the 2019 novel coronavirus (SARS-Cov-2) outside of Wuhan, China: retrospective case series. BMJ 368:m606

2. Chen N, Zhou M, Dong X et al (2020) Epidemiological and clinical characteristics of 99 cases of 2019 novel coronavirus pneumonia in Wuhan, China: a descriptive study. Lancet 395(10223):507-513

3. Zhai P, Ding Y, Wu X, Long J, Zhong Y, Li Y (2020) The epidemiology, diagnosis and treatment of COVID-19. Int $\mathrm{J}$ Antimicrob Agents 55(5): 105955

4. Zhou P, Yang XL, Wang XG, Hu B, Zhang L, Zhang W, Si HR, Zhu Y, Li B, Huang CL et al (2020) A pneumonia outbreak associated with a new coronavirus of probable bat origin. Nature 579:270-273. https://doi.org/10.1038/s41586-020-2012-7

5. King A (2020) An uncommon cold. New Sci 246(3280):32-35. https://doi.org/10.1016/S0262-4079(20)30862-9

6. Doucleef M (2012). Scientists Go Deep On Genes Of SARS-Like Virus. Associated Press. Archived from the original on 2012-0927. Retrieved 2012-09-27.

7. Falco M (2012). New SARS-like virus poses medical mystery. CNN Health. Archived from the original on 2013-11-01. Retrieved 2013-03-16. 
8. Pasley, James. How SARS terrified the world in 2003, infecting more than 8,000 people and killing 774. Business Insider. Retrieved 2020-11-08

9. Li F, Li W, Farzan M, Harrison SC (2005) Structure of SARS coronavirus spike receptor-binding domain complexed with receptor. Science 309(5742):1864-68. https://doi.org/10.1126/science. 1116480

10. The Editorial Board (2020-01-29). "Is the World Ready for the Coronavirus?-Distrust in science and institutions could be a major problem if the outbreak worsens". The New York Times. Retrieved 2020-01-30.

11. Lu H, Stratton CW, Tang Y (2020) Outbreak of pneumonia of unknown etiology in Wuhan China: the mystery and the miracle. J Med Virol 92(4):401-402

12. Organization WH (2020) WHO Director-General's remarks at the media briefing on 2019-nCoV on 11 February 2020. Internet World Heal Organ 5:1-9

13. Mahase E (2020) Covid-19: WHO declares pandemic because of 'alarming levels' of spread, severity, and inaction. Br Med J Publ Group 6:3-10

14. Lu R, Zhao X, Li J et al (2020) Genomic characterisation and epidemiology of 2019 novel coronavirus: implications for virus origins and receptor binding. Lancet 395(10224):565-574. https://doi.org/10.1016/S0140-6736(20)30251-8

15. Yang X, Yu Y, Xu J, Shu H, Xia J, Liu H et al (2020) Clinical course and outcomes of critically ill patients with SARS-CoV-2 pneumonia in Wuhan, China: a single-centered, retrospective, observational study. Lancet Respir Med 8(5):475-481

16. Novel Coronavirus Pneumonia Emergency Response Epidemiology Team (2020) The epidemiological characteristics of an outbreak of 2019 novel coronavirus diseases (COVID-19) in China. Zhonghua Liu Xing Bing Xue Za Zhi 41(2):145-151

17. Mao L, Wang M, Chen S et al (2020) Neurological manifestations of hospitalized patients with COVID-19 in Wuhan, China: a retrospective case series study. JAMA Neurol 77(6):683-690. https://doi.org/10.1001/jamaneurol.2020.1127

18. Keyhan SO, Fallahi HR, Cheshmi B (2020) Dysosmia and dysgeusia due to the 2019 Novel Coronavirus; a hypothesis that needs further investigation. Maxillofac Plast Reconstr Surg 42(1):9

19. Lovato A, de Filippis C, Marioni G (2020) Upper airway symptoms in coronavirus disease 2019 (COVID-19). Am J Otolaryngol 4:102474

20. Hopkins C, Surda P, Kumar N (2020) Presentation of new onset anosmia during the COVID-19 pandemic. Rhinology 58(3):295-329. https://doi.org/10.4193/Rhin20.11

21. Tanasa IA, Manciuc C, Carauleanu A, Navolan DB, Bohiltea RE, Nemescu D (2020) Anosmia and ageusia associated with coronavirus infection (COVID-19) - what is known? Exp Ther Med 20(3):2344-2347. https://doi.org/10.3892/etm.2020.8808

22. Yang X, Yu Y, Xu J, Shu H, Xia J, Liu H et al (2020) Clinical course and outcomes of critically ill patients with SARS-CoV-2 pneumonia in Wuhan, China: a single-centered, retrospective, observational study. Lancet Respir Med 8(5):475-481

23. Chen N, Zhou M, Dong X, Qu J, Gong F, Han Y et al (2020) Epidemiological and clinical characteristics of 99 cases of 2019 novel coronavirus pneumonia in Wuhan, China: a descriptive study. Lancet 395(10223):507-513

24. Guan WJ, Ni ZY, Hu Y, Liang WH, Ou CQ, He JX et al (2020) Clinical characteristics of coronavirus disease 2019 in China. N Engl J Med 382(18):1708-1720

25. Huang C, Wang Y, Li X, Ren L, Zhao J, Hu Y et al (2020) Clinical features of patients infected with 2019 novel coronavirus in Wuhan. China Lancet 395(10223):497-506
26. Kim ES, Chin BS, Kang CK, Kim NJ, Kang YM, Choi JP et al (2020) Clinical course and outcomes of patients with severe acute respiratory syndrome coronavirus 2 infection: a preliminary report of the first 28 patients from the Korean Cohort Study on COVID-19. J Korean Med Sci 35(13):e142

27. Plasschaert LW, Žilionis R, Choo-Wing R, Savova V, Knehr J, Roma G, Klein AM, Jaffe AB (2018) A single-cell atlas of the airway epithelium reveals the CFTR-rich pulmonary ionocyte. Nature 560:377-381. https://doi.org/10.1038/s41586-018-0394-6

28. Bihun CG, Percy DH (1995) Morphologic changes in the nasal cavity associated with sialodacryoadenitis virus infection in the Wistar rat Vet Pathol 32:1-10. https://doi.org/10.1177/030098589503200101

29. Pushpass RG, Pellicciotta N, Kelly C, Proctor G, Carpenter GH (2019) Reduced salivary mucin binding and glycosylation in older adults influences taste in an in vitro cell model. Nutrients. https://doi.org/10.3390/nu11102280

30. Hummel T, Landis BN, Hüttenbrink KB (2011) Smell and taste disorders. GMS Curr Top Otorhinolaryngol Head Neck Surg. https://doi.org/10.3205/cto000077

31. Xu H, Zhong L, Deng J, Peng J, Dan H, Zeng X et al (2020) High expression of ACE2 receptor of 2019- $\mathrm{nCoV}$ on the epithelial cells of oral mucosa. Int J Oral Sci 12(1):8

32. Cheng HY, Jian SW, Liu DP, Ng TC, Huang WT, Lin HH et al (2020) Contact tracing assessment of COVID-19 transmission dynamics in Taiwan and risk at different exposure periods before and after symptom onset. JAMA Intern Med 180(9):1156-63

33. Sakalli E, Temirbekov D, Bayri E, Alis EE, Erdurak SC, Bayraktaroglu M (2020) Ear nose throat-related symptoms with a focus Of loss of smell and/or taste in COVID-19 patients. Am J Otolaryngol. https://doi.org/10.1016/j.amjoto.2020.102622

34. Lechien JR, Chiesa-Estomba CM, De Siati DR et al (2020) Olfactory and gustatory dysfunctions as a clinical presentation of mild-to-moderate forms of the coronavirus disease (COVID-19): a multicenter European study. Ear Arch Otorhinolaryngol 277(8):2251-2261. https://doi.org/10.1007/s00405-020-05965-1

35. Shah NN, Hussain RT, Mustafa $\mathrm{H}$ et al (2020) Evaluation of Olfactory Acuity in Patients with Coronavirus Disease 2019 (COVID-19). Indian J Otolaryngol Head Neck Surg. https://doi.org/10.1007/s12070-020-02241-w

36. Pawluski JL, Brummelte S, Barha CK, Crozier TM, Galea LA (2009) Effects of steroid hormones on neurogenesis in the hippocampus of the adult female rodent during the estrous cycle, pregnancy, lactation and aging. Front Neuroendocrinol 30(3):343-357. https://doi.org/10.1016/j.yfrne.2009.03.007

37. Lennington JB, Yang Z, Conover JC (2003) Neural stem cells and the regulation of adult neurogenesis. Reprod Biol Endocrinol. https://doi.org/10.1186/1477-7827-1-99

38. Lipnicki DM, Sachdev PS, Crawford J et al (2013) Risk factors for late-life cognitive decline and variation with age and sex in the Sydney Memory and Ageing Study. PLoS One. https://doi.org/10.1371/journal.pone.0065841

39. Doty R, Shaman P, Applebaum S, Giberson R, Siksorski L, Rosenberg L (1984) Smell identification ability: changes with age. Science 226(4681):1441-1443. http://www.jstor.org/stable/1693918. Accessed 15 Sep 2020.

40. Kartik Irappa Patil, Rukmini M Prabhu, Priya Jose, Harshitha Chandrashekar, B Viswanatha, (2020) Anosmia and Ageusia in Covid-19 Patients. Sch J Otolaryngol, https://doi.org/10.32474/SJO.2020.05.000211

41. Al-Ani RM, Acharya D (2020) Prevalence of Anosmia and Ageusia in Patients with COVID-19 at a Primary Health Center, Doha, Qatar. Indian J Otolaryngol Head Neck Surg. https://doi.org/10.1007/s12070-020-02064-9 
42. Agyeman AA, Chin KL, Landersdorfer CB, Liew D, OforiAsenso R (2020) Smell and taste dysfunction in patients with COVID-19: a systematic review and meta analysis. Mayo Clin Proc 95(8):1621-1631. https://doi.org/10.1016/j.mayocp.2020. 05.030
Publisher's Note Springer Nature remains neutral with regard to jurisdictional claims in published maps and institutional affiliations. 